\title{
Role of Motivation for Behavior Change in Treatment Retention Amongst a Group of Illicit Drug Users: A Study From Iran
}

\author{
Ameneh Oji, ${ }^{1}$ Faramarz Sohrabi, ${ }^{2}$ Farhad Jomehri, ${ }^{2}$ Omid Massah, ${ }^{3,{ }^{*}}$ and Nader Molavi ${ }^{3}$ \\ ${ }^{1}$ Islamic Azad University, Kish International Branch, Kish, Iran \\ ${ }^{2}$ Department of Clinical Psychology, Faculty of Psychology and Education, Allameh Tabataba'i University, Tehran, Iran \\ ${ }^{3}$ Substance Abuse and Dependence Research Center, University of Social Welfare and Rehabilitation Sciences, Tehran, Iran \\ "Corresponding author: Omid Massah, Substance Abuse and Dependence Research Center, University of Social Welfare and Rehabilitation Sciences, Tehran, Iran. Tel: \\ +98-2122180097, Fax: +98-2122180095, E-mail: omchomch@gmail.com
}

Received 2016 August 16; Revised 2016 October 20; Accepted 2016 October 30.

\begin{abstract}
Background: A change in behavior is one of the most important components of readiness for drug use treatment in Iran.

Objectives: The aim of this study was to determine ones willingness to change and continue treatment amongst patients receiving opium tincture (OT) maintenance treatment in Tehran, Iran.

Methods: This longitudinal study was conducted in 2014. Overall, 140 participants were selected from clients who were referred by a non-governmental organization providing OT, Congress 60, to four drug use treatment centers. At the start of the study, the questionnaire; stages of change readiness and Treatment Eagerness Scale were completed. After three months, participants were divided into two groups of retention and relapse. Data was analyzed using SPSS version 21 and by performing an independent t-test. Results: There was no significant difference between the retention group and relapse group regarding demographic characteristics $(\mathrm{P}>0.05)$. Motivation for change was higher in the retention group compared to the relapse group and their differences were significant $(\mathrm{P}<0.001)$. Group differences between the two groups were statistically significant $(\mathrm{P}<0.001)$ in rates of recognition, ambivalence and taking steps.

Conclusions: In drug-dependent clients, motivation for behavior change is one of the most effective factors for treatment retention. Motivation for behavior change is composed of better recognition of the problem, higher rates of taking steps and less ambivalence in decision making. Further studies are suggested.
\end{abstract}

Keywords: Behavior Change, Drug Dependence, Iran, Motivation, Opium Tincture, Treatment Retention

\section{Background}

In drug use treatment, patients frequently dropping out and low retention rates are serious problems. This leads to a decrease in the drug use treatment rate and an increase in health problems $(1,2)$.

Retention rates in drug use treatment were reported in different studies (1). In Iran, different studies indicated a six-month retention rate of $22.7 \%$ for the MMT program at private methadone clinics (2). In a governmental MMT clinic in Iran, the retention rates at 6 months and 12 months were $66 \%$ and $45 \%$, respectively (3). This figure was among 59.5\% of buprenorphine patients at six months in Iran (4). The above-mentioned rates vary slightly and are less in long-term surveys. For instance, in China, the five-year retention rate in the methadone maintenance treatment program was $0.49 \%$ (1). On average, based on a meta-analysis, combined methadone and buprenorphine maintenance treatment the international annual retention rates were $54.3 \%$; $56.6 \%$ for methadone and $48.3 \%$ for buprenorphine (1). Another study indicated that the average maintenance period amongst patients treated with opium tincture was 232 days (5). These statistics indicate that most of the patients undergoing agonist maintenance therapy leave the program (5). Many factors potentially affect the preparation for drug dependence treatment. Drug users usually drop out of treatment programs, which originate in their poor motivations to change (6). Behavior change is one of the most important factors for treatment willingness and maintenance; in fact, behavior change means applying scientific methods in order to improve behavior through control and change in one's self and his/her environment. Willingness to receive treatment is a sign of motivation, which makes drug-dependent patients enter treatment (7).

Understanding drug dependence as a psychosocial problem by the patient is a strong incentive to enter treatment and continue regular attendance for drug use treatment (8). Perceived obstacles, along with other personal and social issues, might reduce motivation for entering treatment programs and result in continuation of drug use (6).

A study evaluated that characteristics against relapse 
in narcotics anonymous (NA) in Iran concluded that attending NA group meetings had a motivating effect on preventing relapse (9). As mentioned above, many who enter treatment programs drop out after a short period of time and patients need some form of motivation to change their drug use behaviors (10). Opium tincture has come to Iran as a new drug treatment; however, there are few studies regarding patients who receive opium tincture and their motivation to change drug use behaviors.

\section{Objectives}

This study was designed to determine the willingness and motivation for change and to continue treatment amongst patients taking opium tincture for a minimum of three months.

\section{Materials and Methods}

\subsection{Study Design}

This study is a longitudinal research used to determine the willingness to change and continue treatment amongst patients receiving opium tincture maintenance treatment.

\subsection{Study Samples}

Overall, 140 male participants were selected using convenient sampling. Participants were recruited from the congress 60 drug treatment center in Tehran, Iran. The samples were selected from four convenient drug use treatment centers. Congress 60 is a Persian nongovernmental organization (NGO) working in the field of illicit drug use treatment and recovery based on the opium tincture substitution $(11,12)$. The patients' treatment was from March 2014 to June 2014. All participants filled out the stages of change readiness and treatment eagerness scale before entering the treatment plan. The inclusion criteria consisted of signing a consent form, opiate misuse history, voluntary entrance to a drug dependence treatment program, being male and between the ages of 20 to 65. After at least three months of treatment under the study protocol, gaining partial recovery and attempting to maintain change, participants were placed in two groups of retention and relapse for comparisons.

\subsection{Study Tool}

The Stages of change readiness and treatment eagerness scale (SOCRATES) is used to evaluate drugs. In the current study, we used the 19 -item version. Reliability and validity have been reported as 0.78 and 0.80 , respectively. Furthermore, the internal consistency has been reported using the Cronbach $\alpha$ as $0.89(13,14)$. In our study, the Cronbach $\alpha$ total score was 0.86 . This scale is a self-report tool and the respondent must specify his/her agreement level based on a Likert scale ( $1=$ totally disagree and $5=$ totally agree). The scale contains three subscales including 1-Recognition, 2-Ambivalence and 3-Taking steps.

Recognition subscale (individual's motivation to change current situation and curiosity of how to proceed with it) contains seven questions. Ambivalence subscale (having doubts, denying presence of problem, hurt toward him/her or others or uncertainty of taking actions) is composed of four questions. The subscale of taking steps includes eight questions indicating actions the individual has taken before to achieve his goal of quitting drug use and the help, support and guidance he needs in order to achieve his goal. Data gathering was done by psychotherapists working in congress 60.

\subsection{Statistical Analysis}

Data was analyzed by performing descriptive and inferential methods of statistics. In descriptive methods, percentage, mean and standard deviation were performed. For inferential analysis an independent t-test was used. Data analysis was done using SPSS version 21.

\subsection{Ethical Considerations}

The purposes of the study were explained to the participants and they were assured of the study confidentiality. Participation in the study was voluntary and written consent was obtained from all participants.

\section{Results}

Of 140 participants, 66 of them, who were receiving maintenance treatment for more than three months, were considered as the retention group, and the rest $(n=74)$ composed the relapse group (See Table 1).

There was no significant difference between the two groups in the demographic characteristics $(\mathrm{P}>0.05)$. Additionally, the two groups were compared in terms of confounding factors such as general health and addiction severity. They imposed no significant effect on other variables $(\mathrm{P}>0.05)$.

Descriptive statistics regarding sample size, minimum score, maximum score, mean and standard deviation are shown in Table 2.

Mean durations of opiates used were 12.92 years (SD 9.14 ) in the retention group and $9.50 \pm$ SD 7.87 years in the relapse group, respectively.

Based on the Kolmogorov-Simonov test results, data had a normal distribution. Levine's test was conducted to 
Table 1. Demographics of the Two Groups

\begin{tabular}{|c|c|c|}
\hline Variable & Group & No. (\%) \\
\hline \multicolumn{3}{|l|}{ Age } \\
\hline \multirow{2}{*}{$<30$} & Retention & $25(37.9)$ \\
\hline & Relapse & $33(44.6)$ \\
\hline \multirow{2}{*}{$30-40$} & Retention & $19(28.7)$ \\
\hline & Relapse & $22(29.7)$ \\
\hline \multirow{2}{*}{$>40$} & Retention & $22(33.4)$ \\
\hline & Relapse & $19(25.7)$ \\
\hline \multicolumn{3}{|c|}{ Duration of drug use } \\
\hline \multirow{2}{*}{$<5$ years } & Retention & $8(12.1)$ \\
\hline & Relapse & $13(17.6)$ \\
\hline \multirow{2}{*}{$5-15$ years } & Retention & $39(59.1)$ \\
\hline & Relapse & $43(58.1)$ \\
\hline \multirow{2}{*}{$>15$ years } & Retention & $19(28.8)$ \\
\hline & Relapse & $18(24.3)$ \\
\hline \multicolumn{3}{|l|}{ Education } \\
\hline \multirow{2}{*}{$<12$ years } & Retention & $21(31.8)$ \\
\hline & Relapse & $25(33.8)$ \\
\hline \multirow{2}{*}{12 years } & Retention & $31(47)$ \\
\hline & Relapse & $33(44.6)$ \\
\hline \multirow{2}{*}{$>12$ years } & Retention & $14(21.2)$ \\
\hline & Relapse & $16(21.6)$ \\
\hline \multicolumn{3}{|l|}{ Marital status } \\
\hline \multirow{2}{*}{ Single } & Retention & $28(42.5)$ \\
\hline & Relapse & $34(46)$ \\
\hline \multirow{2}{*}{ Married } & Retention & $38(57.5)$ \\
\hline & Relapse & $40(54)$ \\
\hline
\end{tabular}

Table 2. Scores of Subscales in Two Groups of Retention and Relapse

\begin{tabular}{|c|c|c|c|c|c|c|c|c|}
\hline \multirow[t]{2}{*}{ Variable } & \multicolumn{2}{|c|}{ Maximum Score } & \multicolumn{2}{|c|}{ Minimum Score } & \multicolumn{2}{|c|}{ Means } & \multicolumn{2}{|c|}{ Standard Deviation } \\
\hline & $\begin{array}{l}\text { Relapse } \\
\text { Group }\end{array}$ & $\begin{array}{c}\text { Retention } \\
\text { Group }\end{array}$ & $\begin{array}{l}\text { Relapse } \\
\text { Group }\end{array}$ & $\begin{array}{c}\text { Retention } \\
\text { Group }\end{array}$ & $\begin{array}{l}\text { Relapse } \\
\text { Group }\end{array}$ & $\begin{array}{l}\text { Retention } \\
\text { Group }\end{array}$ & $\begin{array}{c}\text { Relapse } \\
\text { Group }\end{array}$ & $\begin{array}{c}\text { Retention } \\
\text { Group }\end{array}$ \\
\hline Recognition & 35.00 & 35.00 & 9.00 & 12.00 & 23.62 & 30.09 & 5.66 & 4.613 \\
\hline Ambivalence & 20.00 & 18.00 & 7.00 & 5.00 & 15.12 & 11.77 & 3.33 & 3.29 \\
\hline Taking steps & 36.00 & 40.00 & 12.00 & 21.00 & 25.06 & 33.56 & 4.77 & 4.04 \\
\hline
\end{tabular}

determine consistency of variances. There were no differences between variances of errors between the two groups including recognition $(\mathrm{P}=0.18)$, ambivalence $(\mathrm{P}=0.97)$ and taking steps $(\mathrm{P}=0.15)$.

There were significant differences between two groups of retention and relapse in the rates of recognition, ambivalence and taking steps respectively (See Table 3). 
Table 3. Independent t-Test, for Means of Recognition, Ambivalence and Taking Steps

\begin{tabular}{|c|c|c|c|c|c|}
\hline Variable & $\begin{array}{c}\text { Retention Group } \\
\text { Means (SD) }\end{array}$ & $\begin{array}{c}\text { Relapse Group } \\
\text { Means () }\end{array}$ & T Value & df & P Value \\
\hline Recognition & $30.09(4.1161)$ & $23.62(5.66)$ & 7.35 & 138 & 0.001 \\
\hline Ambivalence & $11.77(3.29)$ & $15.12(3.33)$ & -5.96 & 138 & 0.001 \\
\hline Taking steps & $33.56(4.04)$ & $25.06(4.77)$ & 11.27 & 138 & 0.001 \\
\hline
\end{tabular}

\section{Discussion}

The aim of this study was to evaluate the role of motivation and willingness for behavior change to continue treatment amongst a group of drug dependent individuals.

There was a significant difference in recognition subscale between individuals in the retention group and those in the relapse group. This is consistent with earlier research done on this subject. Simpson's studies indicated that patients with better recognition of problems remain in treatment more than others $(15,16)$.

Individual's beliefs about his/her illicit drug use, lack of control over drug use, developing physical problems, inability to remedy his/her drug dependence, and hurting self and others have special roles in illicit drug use treatment. In this regard, motivation for continuing treatment is especially important for staying in the treatment program and to have high motivation, better recognition is required (17). Our results are also consistent with this fact. According to the Diclemente et al. (18) findings, in many cases, patients are not able to understand and change themselves and so their external environment and are often in denial. They ignore their problems and never take actions on their decisions. Recognition of the problem and desire for improvement and recognition of the perceived barriers to treatment will lead to more lasting treatment. In line with this view, our study also showed a relationship between recognition and treatment retention.

There was a significant difference between retention and relapse groups regarding the ambivalence subscale. This finding is consistent with previous studies $(10,19)$. Earlier studies have shown that there is not always a linear relationship between attitude and behavior $(20,21)$.

This hypothesis could be explained as individuals who have doubts and hesitations regarding substance dependence, its severity and even existence of lateral problems related to it. They also do not believe in making strides toward recovery. In other words, they cannot correctly evaluate their situation regarding substance dependence and would hesitate to enter treatment programs. These individuals would not last long in the treatment program because of their ambivalence and uncertainty. Above, is the result of the Velasquez et al. (22) research, which agrees with the results of this research.

Additionally, there was a significant difference between the retention and relapse groups in taking steps, which is consistent with other studies. Previous studies showed processes that focus on performance and behavior and how they become more important in later stages of change (maintaining the change). Repeated efforts to change underlie better results in future trials $(10,23,24)$. This is also demonstrated in the current study; those who repeatedly attempted treatment had longer retention in the treatment, however, if they are successful in making changes, they will try hard to maintain the new situation. Despite all the efforts, sometimes patients' lapse and are presented with problematic behaviours, however, most of the time, learning from past efforts regarding change makes it easier to change next time. These results are consistent with previous studies $(6,18,24)$.

This study has a main limitation. It was based on selfreports in collecting data. Further studies are suggested. Conducting a similar study on female population with drug use disorder is also advised.

\subsection{Conclusion}

Motivation for behavior change is one of the most effective factors in treatment retention in drug use disorders. Based on research findings, better situations in components of motivation are associated with treatment retention. On the other hand, better recognition of problems, higher proceedings and taking steps as well as less ambivalence in decision-making leads to more retention in treatment programs. Results suggest that providing these patients with essentials of readiness for change before and during the treatment will help them stay in the treatment.

\section{Acknowledgments}

Authors would like to thank all the individuals who participated in this research. Also, we thank the partner centers of congress 60 that cooperated in this re- 
search. This article has been approved by Kish Azad University in the Persian Gulf region of Iran (proposal No.: 61920701912016).

\section{Footnotes}

Authors' Contribution: Faramarz Sohrabi and Farhad Jomehri conceived and designed the study as well as analyzed the data. Omid Massah and Ameneh Oji gathered the data and drafted the manuscript. Omid Massah developed literature review and discussion. Nader Molavi revised the final edition. All authors read and approved the final manuscript.

Declaration of Interest: None declared.

Funding/Support: This study was supported financially by the Iran University of Medical Sciences, Iran.

\section{References}

1. Feelemyer J, Des Jarlais D, Arasteh K, Abdul-Quader AS, Hagan H. Retention of participants in medication-assisted programs in low- and middle-income countries: an international systematic review. Addiction. 2014;109(1):20-32. doi: 10.1111/add.12303. [PubMed: 23859638].

2. Shirinbayan P, Rafiey H, Vejdani Roshan A, Narenjiha H, Farhoudian A. Predictors of retention in methadone maintenance therapy: a prospective multi-center study. Sci Res Essay. 2010;5(21):3231-6.

3. Moeini M, Razzaghi OM, Mahmoodi M, Pashaeie T. Analysis of retention time among a sample of opioid dependents participating in the Methadone Maintenance Treatment Program in Iran. [in Persian]. J School of Public Health Institute of Public Health Res. 2014;11(3):55-64.

4. Ahmadi J, Bahrami N. Buprenorphine treatment of opiumdependent outpatients seeking treatment in Iran. J Subst Abuse Treat. 2002;23(4):415-7. [PubMed: 12495804].

5. Daneshmand R, Alam Mehrjerdi Z, Samiee M. Maintenance Treatment with Opium Tincture: A Preliminary Qualitative Study of the Factors Related to Treatment entry. Iran J Public Health. 2014;43(8):1123-31. [PubMed: 25927042].

6. DiClemente CC, Schlundt D, Gemmell L. Readiness and stages of change in addiction treatment. Am J Addict. 2004;13(2):103-19. doi: 10.1080/10550490490435777. [PubMed: 15204662].

7. Miltenberger R. Behavior modification: Principles and procedures. Cengage Learning; 2011.

8. Ekendahl M. Will and skill - an exploratory study of substance abusers' attitudes towards lifestyle change. Eur Addict Res. 2007;13(3):148-55. doi: 10.1159/000101551. [PubMed: 17570911].

9. Hedayati N. Protective Individual Characteristics against Addiction Relapse in Narcotic Anonymous of Shiraz, Iran [in Persian].
10. Collins SE, Eck S, Torchalla I, Schroter M, Batra A. Decisional balance proportion: quantifying qualitative data to represent motivation to change among treatment-seeking smokers. Drug Alcohol Depend. 2010;111(1-2):82-8. doi: 10.1016/j.drugalcdep.2010.03.012. [PubMed: 20547012].

11. Zarrindast MR, Sahraei H, Dejakam H. New dimension in drug addiction therapy. Basic and Clin Neurosci. 2010;1(4):68-9.

12. Tavakkoli M, Sahhaf R, Ghaffari S, Farhoudian A, Hayatbakhsh R. Cost Benefit Analysis of Detoxification in Addicts Over 40 in Human Recovery Population (Congress 60). Quarter J Rehabil. 2012;12(0):52-7.

13. Miller W. SOCRATES The stages of change readiness and treatment eagerness scale. Albuquerque: Univ New Mexico; 1995.

14. Miller WR, Tonigan JS. Assessing drinkers' motivation for change: the Stages of Change Readiness and Treatment Eagerness Scale (SOCRATES). Psychol Addictive Behav. 1996;10(2):81. doi: 10.1037/0893164X.10.2.81

15. Joe GW, Simpson DD, Broome KM. Effects of readiness for drug abuse treatment on client retention and assessment of process. Addiction. 1998;93(8):1177-90. doi: 10.1080/09652149835008. [PubMed: 9813899].

16. Simpson DD, Joe G. W. . Motivation as a predictor of early dropout from drug abuse treatment. Psychotherapy: Theory, Research, Practice, Training. 1993;30(2):357. doi: 10.1037/0033-3204.30.2.357.

17. Steensma C, Boivin JF, Blais L, Roy E. Cessation of injecting drug use among street-based youth. J Urban Health. 2005;82(4):622-37. doi: 10.1093/jurban/jti121. [PubMed: 16195471].

18. DiClemente CC, Nidecker M, Bellack AS. Motivation and the stages of change among individuals with severe mental illness and substance abuse disorders. J Subst Abuse Treat. 2008;34(1):25-35. doi: 10.1016/j.jsat.2006.12.034. [PubMed:17574798].

19. Brocato J, Wagner EF. Predictors of retention in an alternative-toprison substance abuse treatment program. Criminal Justice and Behav. 2008;35(1):99-119. doi:10.1177/0093854807309429.

20. Nunn A, Zaller N, Dickman S, Trimbur C, Nijhawan A, Rich JD. Methadone and buprenorphine prescribing and referral practices in US prison systems: results from a nationwide survey. Drug Alcohol Depend. 2009;105(1-2):83-8. doi: 10.1016/j.drugalcdep.2009.06.015. [PubMed: 19625142].

21. Rich JD, Boutwell AE, Shield DC, Key RG, McKenzie M, Clarke JG, et al. Attitudes and practices regarding the use of methadone in US state and federal prisons. J Urban Health. 2005;82(3):411-9. doi: 10.1093/jurban/jti072. [PubMed: 15917502].

22. Velasquez MM, Crouch C, Stephens NS, DiClemente CC. Group treatment for substance abuse: A stages-of-change therapy manual. Guilford Publications; 2015.

23. Otiashvili D, Djordjevic A, Morales D, Parsons A, Platt E, Stempliuk V. Factors related to the process of seeking and completing treatment for drug abuse (qualitative methods in drug abuse research). Georgian Med News. 2005(122):29-32. [PubMed: 15988078].

24. Hallgren KA, Moyers TB. Does readiness to change predict in-session motivational language? Correspondence between two conceptualizations of client motivation. Addiction. 2011;106(7):1261-9. doi: 10.1111/j.1360-0443.2011.03421.x. [PubMed: 21375643]. 